\title{
BURDEN AND QUALITY OF LIFE OF DEPENDENT ELDERLY CAREGIVERS IN PAKUNCEN VILLAGE YOGYAKARTA
}

\author{
Herose Cendrasilvinia, The Maria Meiwati Widagdo, \\ Widya Christine Manus
}

Faculty of Medicine, Universitas Duta Wacana Christian, Yogyakarta

\begin{abstract}
Background: Elderly people face health problems associated with reduced health and increased disability. Dependent elderly on caregivers who cause a burden affecting the quality of life of caregivers. The aim of this study was to analyze the correlation between the burden and quality of life among dependent elderly caregivers.

Subjects and Method: A cross-sectional study was carried out in Pakuncen Village, Yogyakarta. The study subjects were 30 informal caregivers who cared for their family member aged $\geq 60$ years with moderate dependence. Instruments used to screen dependent elderly included Activities of Daily Living (ADL) and Instrument Activities of Daily Living (IADL) to measure level of independence, MMSE and AD-8 to assess cognitive function of elderly. Caregivers aged $\geq 60$ years underwent MMSE and those with scores <24 was excluded. Caregivers' burden ware measured using The Zarit Burden Interview (ZBI) and Caregiver Reaction Assessment (CRA). Measurements of quality of life among caregivers was conducted by WHOQOL-BREF. Data were analyzed using Spearman-rank correlation. Results: Out of 30 caregivers, 24 were female and 6 were male with an average age of 49 years. Most respondents had light to moderate burden (Mean= 34.27; $\mathrm{SD}=18.94$ ). Caregivers' quality of life were low $(<60)$ in psychological (Mean $=58.17 ; \mathrm{SD}=12.31)$, social relation $(M e a n=59.77 ; \mathrm{SD}=9.04)$, and the environment domains (Mean $=51.90 ; \mathrm{SD}=$ 10.00). Caregivers' quality of life was high $(\geq 60)$ in physical health domain (Mean= 63.30; $\mathrm{SD}=12.83$ ). There were negative correlations between caregiver burden (ZBI and CRA) and the quality life of caregivers (WHOQOL-BREF).
\end{abstract}

Conclusion: In Yogyakarta, the burden of caregivers (ZBI and CRA) and the quality of caregivers' lives (WHOQOL-BREF) are negatively correlated.

Keywords: caregiver, burden, quality of life, dependent, elderly

\section{Correspondence:}

Herose Cendrasilvinia. Faculty of Medicine, Universitas Duta Wacana Christian, Yogyakarta. Jl. Dr. Wahidin Sudirohusodo 5-25 Yogyakarta, 55224. Email: herosecendrasilvinia@gmail.com. Mobile: 081226466770.

The $7^{\text {th }}$ International Conference on Public Health Solo, Indonesia, November 18-19, 2020 | 53 https://doi.org/10.26911/the7thicph.01.08 